\title{
Access to veterinary medicines in sub-Saharan Africa
}

1 Glória Jaime ${ }^{1 *}$, Alexandre Hobeika ${ }^{1}$, Muriel Figuié ${ }^{1,2}$

$2 \quad{ }^{1}$ MOISA, CIRAD, ES, Montpellier, France

$3 \quad{ }^{2}$ Faculdade de Letras e Ciências Sociais, Universidade Eduardo Mondlane, Maputo, Mozambique

* Correspondence: Glória Jaime, gloria.jaime@cirad.fr

5 Keywords: veterinary medicine, market chain, access to medication, regulation, sub-Saharan

6 Africa

\section{Abstract}

Background. The significant increase in antibiotics resistance (AMR) has become a major issue over the last decade. Current international focus falls largely on reducing the excessive use and misuse of antibiotics in animal farming. The drivers of this consumption are generally studied through farmers' behavior and veterinary-farmers interactions. However, drug use also results from structural factors that determine the functioning of the drugs market chain and farmers' access to drugs. This article presents an overview of the limits to access to veterinary drugs in sub-Saharan Africa (SSA), as well as the international policy tools and setups that claim to improve it.

Method. We analyze the scientific and grey literature, the publicly available data of the veterinary pharmaceutical industry and international organizations in order to gather information on the veterinary drugs markets in SSA, and on the norms, recommendations, guidelines and initiatives at international level that impact the functioning of the markets chains in SSA.

Findings. We highlight numerous roadblocks to access to veterinary medicines in SSA. The African market is highly dependent on imports. It suffers from a high level of fragmentation, weak distribution infrastructures and services and is driven by the multiplication of private non- professional actors playing a growing role in the veterinary drug chains. The distribution system is increasingly dualized, with on the one hand the public sector (supported by development organizations) supplying small scale farmers in rural areas, but with limited and irregular means; and on the other side a private sector largely unregulated which supplies commercial and industrial farming systems. Different innovations have been developed at the international level to lower these barriers, such as homogenization of national legislations, donations and vaccine banks. Along decades-old inter-state cooperation, many new forms of Public-Private partnerships and hybrid forums are emerging, signaling a growing power of the private sector in the global governance.

Conclusions: In sub-Saharan Africa (SSA), access to veterinary drugs is far from a given and remains an issue for many farmers. Drugs access is highly heterogeneous, little regulated and the market chains are increasingly segmented. The duality of the structure of the market chains has significant implications for the strategies aiming at controlling AMR at global level. Many of them emphasize the need to reduce the use of antibiotics at farm levels, without embracing this duality within countries. These strategies need to take to take into account the diversity of the conditions of access and use of drugs. Policies aimed at regulating the risks associated with the use of some drugs, especially antimicrobials, should not only focus on end users, farmers and veterinarians, but also encompass the actors that influence the flow of these compounds. 
Access to veterinary medicines in Africa

Zoosanitary risks are global threats to human health, agricultural production and trade. In industrialized countries, their control relies heavily on modern veterinary medicines. While these drugs make it possible to manage many of these risks, they can also give rise to new problems such as antimicrobial resistance (AMR), which we has been known since the mid-twentieth century (Gustafson and Bowen 1997). As a global and One Health issue, the fight against AMR has become a salient concern for many international organizations and national governments in the last few years (Cecchini et al. 2015), and one of the main focus of regulation policies for veterinary medicines (Fortané 2016). The main measures aim to increase control on the use of AM medicines in animal farming (OECD 2016, WHO et al. 2017). The reasoning behind this is that resistance to antimicrobials is caused primarily by their over- or misuse (Chantziaras et al. 2014) and since the largest volumes consumed are in farming, it is argued that the use of antimicrobials by farmers and veterinarians should be better regulated.

However, this focus on the reduction of the use of antimicrobials, especially antibiotics, also risks being too general and inadequate for many contexts. Indeed, such measures rely on the assumption that access to the medicines is now a given, including alternatives to antibiotics. As some authors have already highlighted concerning the use of antibiotics in the human sector (Mendelson et al. 2016, Merrett et al. 2016), access to veterinary drugs is still a major issue in low- and middle-income countries (LMICs). Antimicrobial use in these countries is currently reported to be low and mainly therapeutic (FAO 2016). Yet, at the same time, LMICs are often depicted as "hotspots" for AMR (Khan et al. 2019), due their rapidly growing use of antibiotics for animal husbandry (Van Boeckel et al. 2015) and an increasing number of observations of antibiotic resistance in animal farming (Alonso et al. 2017, Van Boeckel et al. 2019). Limited access to alternatives to antibiotics such as vaccines or acaricides, an abundance of counterfeit products, and limited regulation of veterinary drugs, raise questions about their "proper" use in these countries.

We propose to address this contradiction by studying the policy and market structures that determine the use of veterinary drugs. We argue that, when it comes to understanding the drivers of consumption of veterinary medicines, previous studies have tended to emphasize the role of demand, that is the "final" consumers, whether farmers or veterinarians, and overlook the importance of supply.

Many previous studies on veterinary medicines in LMICs have dealt with demand. Initially, research focused on local knowledge, ethno-veterinary medicines or medical syncretism as an alternative to modern veterinary drugs (Bonfiglioli 1982, McCorkle 1995, Mwale and Masika 2009). More recently, a second wave of research has developed in relation with a growing interest in AMR, questioning the use and perception of veterinary drugs and more specifically antibiotic use by farmers (see for example Chauhan et al. 2018, Dognon et al. 2018). Despite recognizing the numerous determinants of veterinary drug use, these bodies of work give prominence to cognitive and psychological drivers of farmer behavior and tend to blame farmers and sometimes veterinarians for not complying with the "proper" use of veterinary medicines. Related recommendations or experiments focus on testing how information and communication interventions might help increase farmers' awareness of and knowledge on this use and the related risks (Roulette et al. 2017).

Most research on the supply side of veterinary medicine use in Africa focuses on the weaknesses of the veterinary health systems. It advocates the reinforcement of the network of "community health workers" or para-vets and documents the socio-economic conditions that make such goals pertinent. We argue that while such semi-professionals help farmers, they are also limited by the medicines they 
on the structure of the veterinary drugs market. Indeed, the organization of market chains is a key factor in the availability, diversity, quality, and affordability of drugs, factors that impact the consumption patterns. Widening the scope of the analysis to include the functioning of this market is thus necessary to understand the determinants of the use of antibiotics and of potential alternatives such as vaccines. Whereas a lot of academic attention has been given to the accessibility of medicines for human health in LMICs (Reynolds Whyte et al. 2002, Peterson 2014, Baxerres et al. 2017, Quet 2018, Abecassis and Coutinet 2019), knowledge about veterinary drugs lags far behind and a broad overview of the different determinants of access to veterinary medicines is missing. We aim to bring the question of access to drugs into discussions on AMR in order to better understand the complex drivers of veterinary drug use and to support the design of policies that better balance the curbing of misuse with an increase in access.

\section{Materials and methods}

The goal of this article is, first, to discuss the availability of veterinary medicines in countries where the market chains for drugs are poorly structured and regulated, and, second, to present an overview of the contemporary policy instruments that have emerged at the international level to facilitate access to veterinary medicines in LMICs. This notion of access refers to three dimensions: availability, quality and affordability. It highlights the variations and inequalities inside countries and the structural factors that limit low-income farmers' choice, and minimizes the role of individual attitudes and perceptions as social determinants of consumption patterns.

We focus on sub-Saharan Africa (SSA), a region with a large number of LMICs and the largest diversity of animal farming systems. Data on the veterinary drugs market, in particular in LMICs and in sub-Saharan Africa, is scarce and sometimes inconsistent. However, on the whole, the use of veterinary drugs in SSA is depicted as low and heterogeneous between and within countries, and the issue of access to drugs is particularly acute. In LMICs, extensive and smallholder producers predominate. In sub-Saharan Africa it is estimated that 300 million people living in rural poverty depend on livestock (ILRI 2012) (and one billion worldwide). Availability of and accessibility to veterinary drugs and services is problematic for the majority of farmers (Roger and Ducrot 2017). According to Crosia (2011), the consumption of veterinary drugs in sub-Saharan Africa accounted for less than 3\% of the world market in 2009, half of which was South Africa alone (Grasswitz et al. 2004). We will focus here on the market chains of veterinary drugs for production animals and set aside drugs for pets. While drugs for pets represent an important and growing market ( $42 \%$ of the world market for vet drugs in 2009 according to Crosia 2011), this is mainly concentrated in western countries.

We use a socio-economic definition of modern veterinary medicines, as socio-technical objects in market chains. Firstly, as socio-technical objects, these therapeutic compounds differ from "traditional" medicines in that they are industrial products: they are the product of industrial and commercial logics that define and constrain the market chain throughout, must comply with sanitary norms and are identified by protocols of control, measure and certification determined on a global scale. Such a definition shifts the emphasis from the question of curing animals, to who can control, enable and prevent the flow of molecules to the users. It allows us to study both the policies on access to drugs and the regulation of their use. What we call market chains are the set of activities carried out by various economic entities, from the conception of a product to its final use. This includes research and development, production, wholesale, retail, and uses of the drugs. We use a general understanding of this notion, which also includes all the actors who contribute indirectly to the circulation of drugs, by drafting norms, rules and recommendations that influence the organization and functioning of the market chain. 
128 This article is an exploratory study based on an analysis of all the sources we could find, but does not

129 claim to be exhaustive.

130 The first group of sources are texts by experts on the subject in technical reviews (e.g. Revue 131 Scientifique et Technique de l'Office International Des Epizooties), in grey literature (e.g. reports for 132 AU-IBAR), or veterinary pharmaceutical industry websites (e.g. the website of HeathforAnimals). 133 These sources provide information on the world market of veterinary drugs (Crosia, 2011, Grasswitz 134 and al 2004), the regulation of these markets (Smith, 2013 ; Blancou and Truszczynki, 1995 ; 135 Thompson, 1999), the processes of harmonization of technical specifications at an international level 136 (Blancou and Truszczynski 1995, Holmes and Hill 2007, Le Minor 2011), the veterinary infrastructures 137 that support the distribution through to end users, and the potential to improve access to vet services 138 through veterinary paraprofessionals (Cirad and VSF 2003, Catley et al. 2004, Niang 2004, Luseba and 139 Rwambo 2015, Magnani et al. 2018).

140 A second group of sources is made up of academic work addressing the social dimension of antibiotic 141 use for farmed animals. These studies were prompted by the recent spike in attention given to the issue 142 of antimicrobial resistance in international and national policy agendas. They are published mainly in 143 veterinary journals that do not aim directly to publish social sciences research (see for example 144 Hockenhull et al., 2017; Goutard et al. 2017, Coyne et al. 2018), and more pioneering ones in social 145 science journals (Fortané et al. 2015, Lhermie G. 2015, Dangy and Fortané 2016, Fortané 2020). Yet 146 there is a limited number of works focused on LMICs (Masud et al. 2020).

147 A third group of sources is made up of the norms produced by international sanitary organizations. 148 This category includes recommendations, guidelines, norms, directives and agreements diffused by 149 entities like the World Organization for Animal Health (OIE), Food and Agriculture Organization 150 (FAO), World Trade Organization (WTO) as well as Veterinary International Committee for 151 Harmonization (VICH). They operate in various fields, such as the production of codes of practice and 152 quality standards (from production to use of drugs), the harmonization of the national 153 licensing/registration procedures and the assessment of the national veterinary services' capacity to 154 exercise control over veterinary medicines.

\section{Results and discussion}

\section{$156 \quad 3.1 \quad$ Veterinary drug market chains in sub-Saharan Africa: roadblocks to access}

157 We examine the factors limiting the access to veterinary drugs in SSA, by following the market chains, 158 from production to use. The veterinary drug market is globalized and dominated by less than ten 159 American and European pharmaceutical industries. This market is dynamic, benefiting from the 160 growing demand from the pet sector in the Western countries, and the growing number of farmed 161 animals in the emerging Asian countries. However, there is a lack of corporate interest for the African 162 market. Production of medicines in SSA is scarce, except for the easy to produce vaccines and generic 163 drugs. It can be explained by the fact that the African markets are of limited size, with a low purchasing 164 power, highly fragmented and poorly regulated. Inside countries, distribution infrastructures and 165 professional advice are insufficient, due to structural adjustment programmes in the 1980s, and the market chain sees a rise in non-professional actors. This leads to consumption practices that have to adapt to low-quality drugs, about which farmers have uncertain information. 
Access to veterinary medicines in Africa

168

169

170

171

172

173

174

175

176

177

178

179

180

181

182

183

184

185

186

187

188

189

190

191

192

193

194

195

196

197

198

199

200

201

202

203

204

205

206

207

208

209

210

211

212

\subsubsection{A market dependent on imports and highly fragmented}

It is difficult to access reliable data on veterinary drug market chains in sub-Saharan Africa (SSA). This information is not freely shared by the economic actors involved and any available statistics are likely to only record part of the circulation of veterinary drugs. Available studies (Grasswitz et al. 2004, Crosia 2011) describe the African veterinary drugs market as small (3\% of the world market) and highly dependent on imports ( $80 \%$ comes from outside of the continent), and more than half of this market is concentrated in South Africa.

The production of modern veterinary drugs requires a large-scale market due to the diversity of needs for different farmed animal species (contrary to the human drug market) and the diversity of farming systems. Market fragmentation is aggravated by a lack of harmonization in national regulations. Some countries have passed laws, more or less recently, concerning the markets for veterinary drugs (Grasswitz et al., 2004). These policies are mostly adaptations of the norms and guidelines issued by international organizations, but are often insufficient, incomplete (see the OIE PVS country reports), rarely updated or else are "imported" from other countries and thus are mis-adapted to the importing countries, due to the lack of scientific and financial resources in the administration.

Moreover, international "good manufacturing practices" guaranteeing quality may be difficult to implement in some national contexts. These factors help explain why strategies for developing local production in SSA are constrained. The production of veterinary medicines in Africa is limited to few countries, such as Morocco (the Moroccan production covers $90 \%$ of national needs but represents just $0.12 \%$ of the world market (L'Économiste, 2008)). In SSA, few countries have private drug manufacturers (they are mainly tertiary manufacturers), like Bupo Animal Health (formerly Bedson) in South Africa, Cooper-K in Kenya, or the capacity to even partly supply neighboring countries. The industry possesses a de facto monopoly over the practical knowledge and technological structures necessary to convert medical discoveries coming from basic research into therapeutic products (Gateaux and Jean-Michel 2008). Public veterinary structures, depending on the ministry of agriculture, also manufacture a reduced number of easy-to-produce generic medicines to support veterinary public health activities, such as vaccination campaigns or parasite control (e.g. Ethiopia with vaccines against Newcastle disease and acaricides, Zambia with rabies vaccines, see the OIE WAHIS data). Regional cooperation exists, such as the Pan-African Veterinary Center of the African Union (AU-PANVAC) in Ethiopia that produces biological reagents for animal disease diagnosis (and also provides independent quality control of veterinary vaccines).

Therefore, most of the veterinary drugs consumed in SSA are imported, mainly from Europe, the US, Brazil and, increasingly, China and India, with a complex organization between primary, secondary and tertiary manufacturers and export and re-export processes that still need to be clarified. Most of these products are imported by national distributors and only a few of the big pharmaceutical companies have established branch offices in SSA. This includes Elanco Animal Health (Bayer, Boehringer Ingelheim), Virbac, Zoetis, and MSD Animal Health, which have all established branch offices (subsidiaries) in South Africa. Elanco Animal Health (the group bought the veterinary branch of Boehringer Ingelheim in 2016, and Bayer in 2019) has the most extensive presence on the continent, with subsidiaries also in Angola, Kenya, Mozambique, Zambia and Zimbabwe. These companies generally seek to develop medicines that promise a high return on investment and target mainly the intensive farming systems (e.g. poultry and pork) supplying the emerging middle class of urban consumers, which leads to neglecting other diseases.

These examples show how fragile the African market remains and highlights the lack of corporate interest in the African market, except for a few countries such as South Africa. This can be explained 
213 by the size of national markets, which remain limited in SSA. Most farmers have low purchasing

214 power: according to the International Livestock Research Institute (ILRI), poverty is widespread 215 among African livestock owners, and this limits the affordability of modern veterinary medicines.

216 Moreover, compared to emerging Asian countries engaged in the livestock revolution (Delgado et al. 217 1999), low input farming systems remain predominant in SSA. This is the case in particular in pastoral

218 areas, where farmers have limited and uncertain access to markets and cash and are exposed to external

219 risks such as climate-related risks.

\section{$220 \quad$ 3.1.2 Weak distribution infrastructures and services}

221 Infrastructure and services are necessary for the advice and distribution of goods to their final users. In most SSA countries, access to veterinary medicines was provided by a centralized public sector inherited from the colonial period (Magnani et al. 2018), managed by the veterinary profession and based on a populational approach to animal health (Landais 1990). However, in the 1980s, under pressure from the World Bank, most developing countries adopted structural adjustment programs (SAPs) taking a market approach as the preferred means of providing services, whilst at the same time reducing state expenditure. This led to a drastic shift of responsibility from the public to private sector, including veterinary drug deliveries and veterinary services (Luseba and Rwambo 2015, Ilukor 2017).

This process has been extensively analyzed and discussed in several international forums and publications (FAO, 1997, Daborn et al., 1998, Silkin \& Kasirye, 2002, Grace \& Leyland, 2002, Umali, Feder, and de Haan 1992, Cheneau 2004). These studies conclude that only a handful of countries and a small proportion of producers have benefited from this privatization process: reductions in public veterinary services have not been fully offset by private veterinarians (in particular when it comes to the distribution of veterinary drugs in rural areas) and this gap in the market has been filled by a variety of unprofessional actors.

236 There is little incentive for private veterinarians and pharmacists to provide services in areas where the 237 veterinary drug use per cattle head is low, purchasing power is limited, animals are widely dispersed, and transaction costs are high. They are more likely to commit to sectors where revenue is higher, such as the emerging market for pet health in cities or the burgeoning sector of intensive animal production in peri-urban areas (Cheneau et al, 2004, McLeod \& Wilsmore, 2002, Thome et al. 1995).

Public veterinarians are few and far between. Mozambique, for example, is estimated to have only about half the number of public vets it needs. In addition, their capacity to deliver veterinary services and medicines is low. They suffer from inadequate and unpredictable budgetary allocations and drug supply and have limited capacity to visit farmers (CIRAD and VSF 2003). Their role as drug suppliers is restricted to the delivery of vaccination and parasiticides during outbreaks. Rates of absenteeism are high and opportunities for career progress limited. Some of these veterinarians work in parallel in private clinics, selling drugs and delivering therapeutic individual care for pets and farmed animals. This partly makes up for the absence of the private sector but also contributes to blurring the lines between public and private services.

\subsubsection{The multiplication of non- professional actors in the veterinary drug chains}

To support veterinary medicine delivery and services, new business models and institutional arrangements have emerged, such as cost recovery for public veterinary services and contract farming with private companies. This movement is also sustained by the training of para vets, supported by donors, and by the development of an informal sector (Ilukor 2017). This shift has affected the types and quality of drugs and the related services available to farmers. 
Paraprofessional agents provide farmers with basic veterinary services in rural areas. Their knowledge relies on short training by public veterinary services and NGOs (Diop and Bessin 2004). They are encouraged to develop a private veterinary drug supply system to finance their activities in the long run. This system has been quite successful in different contexts (Rubyogo et al. 2005), but it also suffers from many constraints (Peeling and Holden 2004) such as irregular supply, the low purchasing power of farmers and transport difficulties. Moreover, NGOs and internationally funded projects may carry out free distribution of medicines and vaccines, which sometimes undermine attempts at privatization and payment by beneficiaries.

The liberalization of veterinary drug distribution has also encouraged the emergence of alternative chains of supply made up of a large number of middlemen (Daborn C. and al 1998, FAO, 1997, Clark, 2012, Sunderji, 2017), mostly in peri-urban areas. In these areas, animal production is developing in conjunction with the increasing demand of urban consumers for meat and a process of intensification supported by urban investors or by producer organizations (e.g. commercial poultry farmers associations). These areas concentrate the private markets for veterinary medicines.

Public as well as private veterinarians are involved in these private market chains. Some participants only have practical knowledge of drug use (e.g. commercial poultry farmers), while others do not have any knowledge at all but have capital they wish to invest in growing markets. Frequent failures have been observed in veterinary administration and regulation, which have left the private market chains unregulated (from imports to retail), and many drugs are sold without prescription. As a consequence, veterinary medicines are sometimes found everywhere, but also anyhow. Therefore, even in the context of relative abundance, access to quality and appropriate drugs remain problematic.

\subsubsection{Low diversity and quality among available drugs}

The organization of a market chain has a significant impact on the availability and accessibility of appropriate and quality drugs and, consequently, on veterinary drug consumption patterns, including antibiotic consumption.

Despite significant and diverse production of veterinary drugs globally, this production does not cover all the needs of the African markets. SSA countries do not contribute to the R\&D dedicated to veterinary drugs. As in the human health sector (Coutinet and Abecassis 2018), diseases endemic to Africa receive little attention from "Big Pharma", which raises the issue of neglected animal diseases (Roger and Bonnet 2015). Offer is also limited by the low training level of the para-vets. Consequently, their ascribed role in delivering medicines is officially generally limited to drugs that can be sold over the counter or with a broad- spectrum (for example oxytotetracycline, for antibiotics). The privatization of drug distribution encourages the sale of products, such as antibiotics, that offer a high margin rather than those most needed.

The low diversity of the available medicines encourages "off-label uses". This term refers to the use of a drug in a way that is not recommended on the label or package insert (Smith 2013). This off-label use may cover other indications, routes of administration, species, age groups, etc. This practice also includes diverting the use of human medicines, particularly when human medicines are more available and affordable, which can be the case when different countries adopt economic policies including low import taxation and subventions in order to improve access to human drugs.

Diverted and "off-label" uses of drugs encourage inappropriate use, in particular when technical supervision and an effective regulatory framework are lacking. For example, veterinary services in Madagascar have reported the use of injectable contraceptives intended for women (progestogens 
Confiance ${ }^{\mathrm{TM}}$, Pfizer), easily available at a low price, as an alternative for surgical castration of adult sows before culling (Porphyre et al. 2013). Misuse is also fostered by unsuitable packaging, for example labels in foreign languages or when small-scale farmers only have access to 1000-doses Newcastle-disease vaccines while their flocks are much smaller.

303 Sub-standard and non-registered drugs are also an issue. The market for illegal drugs (sub-standards and non-registered) is estimated to be worth 400 million US dollars a year in Africa and one to two billion US dollars worldwide (Kingsley 2012, HealthforAnimals 2017). Institutions for drug quality control are sorely lacking and only a few countries with significant production capacities (South Africa, Botswana and Ethiopia) have properly equipped control laboratory facilities. Other countries such as Uganda and Zimbabwe use laboratories, often set up with support from the WHO, designed for the control of human medicines (Grasswitz et al., 2004). The lack of quality controls and of reliable sign of quality does not allow farmers to make the difference between high-quality and low-quality drugs. This discourages the sale of high-quality products, leading to an adverse selection on the market where bad products drive out the good ones (Akerlof 1970).

313 Quality problems are diverse: from lower concentrations of active ingredients than that listed on labels to toxicity. According to a survey conducted in West Africa by the veterinarian faculty of Dakar and quoted by Le Minor (2011), 67 and $69 \%$ of the veterinary drugs sampled in the formal and informal sectors respectively were of sub-standard quality; the sub-standard drugs were mainly trypanocides and antibiotics (oxytetracycline). The low purchasing power of farmers encourages drug sellers to work with lower cost suppliers and sometimes to dilute drugs, leading to concentrations that are too low. These practices can encourage farmers not to comply with recommendations. For example, pastoralists in Cameroon have been reported (Vougat Ngom et al. 2017) to use antibiotics in subtherapeutic doses, as a logical adjustment to sellers diluting the drugs.

The development of informal market chains (involving non-registered stakeholders) selling illegal or counterfeit drugs is encouraged by the low availability and affordability of modern standardized drugs. This question has been highly debated in the human drugs sector. The informality refers to the unregistered status of the actors or goods with no systematic negative impact on the intrinsic quality of the drugs themselves. Researchers have underlined the usefulness of these informal markets in addressing gaps in legal market chains (Baxerres 2014) and denounced the manipulation of the debate around counterfeit drugs as an attempt by "Big Pharma" to protect its market of branded drugs against new players. The relevance of this analysis to veterinary drug markets is yet to be documented.

There is thus a lack of corporate interest for the African market. Internal factors also explain the low attractivity of this market for investors: it is limited by the low purchasing power of farmers and fragmented by heterogeneous legislations. The organization of the market at national levels is dual, with heterogeneous public and private supply chains, both suffering from numerous weaknesses that affect the availability and quality of the drugs available for farmers.

\section{$335 \quad 3.2 \quad$ International actions and setups improving access to drugs}

Various institutional forms have emerged over time at the international level to support the countries in circumventing these difficulties of access to drugs, and to coordinate and harmonize their actions. They can directly improve access to veterinary drugs, promote the regulation policies of international organizations, and mobilize the pharmaceutical firms. The market chains of modern veterinary drugs are framed by setups that have been promoted and institutionalized by international organizations (the OIE, FAO, Codex Alimentarius, VICH, etc.), following the WTO agreements on Sanitary and Phytosanitary (SPS) measures (Thompson, 1999, Smith, 2013, Blancou and Truszczynki, 1995). 
343 Norms emitted by VICH and Codex Alimentarius also provide countries with a set of norms in order

344 to regulate production, marketing authorizations, trade, and use of veterinary drugs. Bilateral and 345 regional agreements also contribute, in the forms of donations and vaccine banks. Aside from inter346 state cooperation, we note a rapid increase in initiatives where the private sector, especially 347 pharmaceutical companies, plays a central role. These setups rarely include research and development,

348 however, and act mainly on trade and veterinary advice rather than on the production side.

349 We focus here on the international level. Important efforts are also carried out at the national level, for instance price subsidies, taxes, flexibilities in the Trade-Related Aspects of Intellectual Property (TRIPS) agreements. They exceed the scope of this paper: their usage exists within a framework of international cooperation in which animal health is considered a global public good, and whose dynamics we want to emphasize.

\subsubsection{A slow homogenization of national regulations}

Although national regulations are diverse, and can be insufficient or mis-adapted, several international organizations act in order homogenize them. We start by presenting the established international institutions, of which most countries in the world are members, then most recent initiatives.

The OIE, established in 1924, is a major actor in this field. It institutionalizes the sanitary norms for international trade of cattle and animal products, which member states can use to prevent the introduction of diseases and pathogenic agents without creating unjustified sanitary barriers (Orand, 2012, Smith, 2013). For example, working on the basis of the Sanitary Code for Terrestrial Animals, it formulates guidelines for the prudent and responsible use of antimicrobials in veterinary medicine (Smith, 2013). It also promotes the increase in professional veterinary capacities and the participation of veterinary services in the design of regulations.

365 International trade of modern veterinary drugs is subject to norms set by the WTO. Through the SPS agreement, enforced since 1995, the WTO seeks to reduce state use of measures that could be deemed unjustified and protectionist (WTO, 2012), which contributes to increasing the availability of the drugs.

The Codex Alimentarius, a joint programme of FAO and WHO established in 1963, acts from the perspective of food safety. As per veterinary medicine, it develops norms concerning the maximum residue limits of drugs in food, and by this means regulates the use of medicines in farming worldwide, by the end of the market chain (FAO and WHO, 2015).

$\mathrm{VICH}$ is one of the main organizations setting internationally recognized norms for veterinary drug registration and marketing authorization (Smith, 2013, Thompson, 1999). Established in the mid-1990s by industrialized countries (European Union, USA, Japan), it is currently expanding as a more global forum. It promotes international standards for the definition of criteria that the national authorities should use in examining requests (Blancou and Truszczynki, 1995) and aims to guarantee the respect of procedures of controls and data collection, including pharmacovigilance, after the marketing authorization has been granted. Therefore, its action can be seen as contributing to the quality of drugs in SSA, by a transfer of expertise on their sanitary properties - with the caveat that, by design, marketing authorizations are dependent on the data provided by the pharmaceutical companies 381 (Marion, 2011).

382 GALVMed is a non-profit structure, with the status of charity, initiated in the early 2000s by the United 383 Kingdom Department of International Development (DFID) and also supported by the Gates 384 Foundation. It has now established as an important organization in the field, and partners with FAO to 
385

386

387

388

389

390

391

392

393

394

395

396

397

398

399

400

401

402

403

404

405

406

407

408

409

410

411

412

413

414

415

416

417

418

419

420

421

422

423

424

425

426

427

improve research, quality, and access of vaccines and veterinary medicines. In particular, it has worked on documenting the registration process and legislation per country in SSA (GALVMed, 2015), and harmonize regulations in East Africa (GALVMed, 2016).

\subsubsection{Donations}

Donations are a direct way to facilitate access to veterinary drugs in developing countries. Governments, private companies or NGOs enact them, in three main situations: in emergencies, as part of development aid and programs, and as donations of returned and unwanted (almost-expired) pharmaceuticals (Schouten 1995, Hogerzeil 1997, Clark and Embrey 2012, Guilbaud 2015a), which can act as tax deductions (Guilloux and Moon 2001).

To illustrate their importance, we can give the example of the foot-and-mouth disease (FMD) vaccines Botswana donated to Zimbabwe in 2017 as part of a development aid package. Botswana donated over 400,000 doses, manufactured by the Botswana Vaccine Institute, in order to help the country and avoid negating efforts made to eradicate FMD in zones where Botswana shares a border with Zimbabwe. According to Clark and Embrey (2012), on the one hand, this type of donation is the most favorable for all parties, because it takes into account the explicit needs of the beneficiary. On the other hand, the same authors argue that donations made in the context of sanitary emergencies can land the beneficiaries in unfavorable situations, for example if they receive almost-expired vaccines or drugs or even pharmaceuticals not relevant to the emergency, type of disease, or level of available care.

According the WHO (1999), donations should respect four core principles: maximum benefit to the recipient, respect for the wishes and authority of the recipient, no double standards in quality and effective communication between donor and recipient. These principles aim to improve the quality of pharmaceutical donations. Beyond these principles, the donations of veterinary products have to comply with the internationally recognized norms and guidelines in order to ensure the safety and quality of the donations. For the human health domain, these norms were developed in 1990 by the WHO in cooperation with the Christian Medical Commission of the World Council of Churches (Clark and Embrey 2012). To date, however, no specific framework has been established for the veterinary domain. Hogerzeil (1997) argues that they are not international regulations but are intended to serve as a basis for national or institutional guidelines, to be reviewed, adapted, and implemented by governments and organizations dealing with pharmaceutical donations.

Overall, donations play a key role in improving the supply of veterinary drugs. On a global scale, many donations are made by different governmental and non-governmental entities to respond to all health issues. However only limited information is available on their overall scope. Donations of drugs, for example, can also be made through vaccine banks (for vaccines) and public-private partnerships (for all drugs).

\subsubsection{Vaccine banks}

Vaccine banks were defined by the OIE (1992) in its Manual of Tests and Diagnostics and Vaccines for Terrestrial Animals (chapter 1.1.10) as "reserves of antigens or vaccines of various types". They can work as banks which store the antigenic content, the vaccine in a formulated and ready-to-use form, or both (OIE 2018a). In general, they enable the management of stocks of vaccines, with the aim of solving availability problems, whether they stem from difficulties in obtaining a marketing authorization or from difficulties controlling stock in beneficiary countries.

Vaccine banks improve the feasibility of emergency vaccination by guaranteeing supplies of highquality vaccines, manufactured according to international norms, to the benefit of the recipient 
countries (OIE 2018a). Vaccines can be deployed from servicing contracts established between the bank and demanding countries, in case of systematic mass vaccination campaigns, as well as in cases of emergency vaccination, or strategic interventions by a country (Lombard and Füssel 2007, OIE 2018a). According to the OIE (2018a) they must comply with a list of guiding principles, which include: supporting the implementation of the OIE-adopted strategies against diseases; having a transparent selection process and guaranteeing the supply of high-quality vaccines; responding to demands of the countries; being flexible and without financial risk; and prioritizing partnerships.

To illustrate their role in the supply of vaccines and management of stocks, we can take the example of the OIE vaccine banks. They are created in response to international calls and can be seen as a hybrid mechanism that corresponds to a supply agreement between the OIE and laboratories. The OIE has vaccine banks targeting Avian Influenza in Africa and Asia, FMD in South East Asia, rabies in Africa, and Peste des Petits Ruminants (PPR) in Western Africa (Tagliaro 2016, OIE 2018c). The PPR bank in Africa, created in 2013 under the Vaccine Standards and Pilot Approach to PPR Control in Africa Project (VSPA), was funded by the Gates Foundation and the World Bank through the Regional Sahel Pastoralism Support Project (PRAPS) (OIE 2018b). The Botswana Vaccine Institute (BVI) has been the supplier of vaccines to the PPR Vaccine Bank for Africa. It made available 14 million doses of PPR vaccine and the corresponding quantities of vaccine diluent for Burkina Faso, Ghana, Mali and Togo. Therefore, it guarantees the supply of quality vaccines against PPR and has facilitated the harmonization of methods of fighting PPR in Africa. The OIE also has a virtual vaccine bank, which aims to help infected countries to react quickly and non-infected countries to prepare a strategic stock in order to protect their disease-free status (OIE, 2018a). This tool has been designed to avoid possible losses of vaccines due to their expiration.

Regional organizations can play a part as well. The Continental Veterinary Vaccine Bank has been created in 2018, by the African Union and its Pan-African Veterinary Vaccine Center (PANVAC), with the support of FAO, OIE, the EU, the Gates Foundation, USAid, GALVMed, and some countries. It focuses mainly on the prevention of a resurgence of Rinderpest (AU, 2018).

\subsubsection{Public-private partnerships}

455 Public-private partnerships (PPPs) have been a rapidly growing form to improve access to veterinary drugs, over the last decade. They are defined as "a collaborative approach in which the public and private sector share resources, responsibilities and risks to achieve common objectives and mutual benefits in a sustainable manner" (Thevasagayamn et al. 2017, OIE 2019). They are based on the assumption that private actors can have a positive influence on the efficiency of public sector organizations or of the new system formed under the partnership (Buse and Walt 2000). This category encompasses a wide range of forms and can vary according to factors such as: the number of partners involved, type of interaction, objectives, modalities, region of implementation, governance mechanisms, intensity and intended duration (Buse and Walt 2000, Galière et al. 2019). PPPs are now also thought of as tools to improve quality of and generate innovations in veterinary services. manual, PPPs enable the development of animal health services, policies and trade to a scale, quality or degree of geographic penetration that would be unattainable for the public sector alone. They also aim to contribute to improving access to drugs, reinforcing veterinary services, inciting technology transfer agreements, and increasing R\&D activities on new drugs (Buse and Walt 2000, Guilbaud 2015a, Galière et al. 2019, OIE 2019). At the same time, they have to abide by the ethical principles set out by the WHO: benefactor intention (guarantee public health), non-malevolence (the 
implementation of the PPP should not create new public health problems), autonomy of all partners,

473 and equity (the main benefits of the PPP should go to those most in need).

474 In the last few years, PPPs have been increasingly promoted by different actors (governments, internationals organizations, NGOs, private companies, philanthropic foundations), especially the Gates foundation and OIE in the last few years. At an international level, the importance of PPPs has been well documented by many authors who note that PPPs are testimony to the increasingly proactive involvement of the private sector in global decision-making processes, including the interests of the UN (Buse and Walt 2000, Ndour 2006, Barry et al. 2014, Guilbaud 2015b). In this way, private actors can take part in the production of non-binding norms, which have some degree of influence on traditional international law. In the veterinary field, their importance has been further emphasized in the OIE Performance of Veterinary Services (PVS) pathway diagram (Galière et al. 2019), but a limited number of examples of PPPs are available.

One example would be the PPP initiated by the Gates Foundation and Zoetis in 2017, within the framework of the African Livestock Productivity and Health Advancement (ALPHA) initiative. The Gates Foundation provides \$14.4 million over three years (later extended to five years until 2022) to bolster the sustainable growth and development of the farming sector in SSA (primarily in Nigeria, Ethiopia and Uganda and now Tanzania) (Zoetis 2019). It targets improving access to veterinary drugs and services, providing training and education, and implementing diagnostic infrastructure to ensure people are not only receiving help but also understanding the relationship and results (Zoetis 2019). The role of the pharmaceutical firm was to establish basic infrastructure, including hiring a team to address regulatory and technical issues; increase the reliable supply of quality veterinary medicines, diagnostics and services; engage with local farmers and veterinarians to ensure sustainable solutions; develop veterinary laboratory networks and dialogue with government stakeholders to understand local requirements and needs, including regulatory issues (Zoetis 2019). This example suggests that PPPs can be complementary to public action, which could provide some of the efficiency, management capacities and culture of evaluation of the private sector. The possible cost is a long-term loss of sovereignty of the state in the veterinary policy and rent situations. As it has been extensively documented, PPPs do not systematically create "win-win" situations (Buse and Walt 2000, Ndour 2006, Guilbaud 2015b), but they provide an opportunity for various actors to take on a role in the elaboration, interpretation and implementation of global regulations on trade and sanitary norms.

\section{Conclusion}

503

504

505

506

507

508

509

510

511

512

513

514

The sub-Saharan African drugs markets are little attractive for international pharmaceutical companies and remain peripheral to the global markets for modern veterinary drugs, except South Africa, where most of the market is concentrated. The markets chains are little regulated and highly fragmented in terms of registration procedures and market authorization. The distribution chains are weak economically and lacking in professionals, as a consequence of the wave of privatization of veterinary services seen in the $1980 \mathrm{~s}$. As a consequence, we see a dual system for veterinary medicines. On the one hand, the public sector, supported by development organizations, supplies small scale farmers, mainly in rural areas, but with limited and irregular means. It focuses on the distribution of vaccines and parasiticides through large scale campaigns. On the other hand, the largely unregulated private sector supplies the growing commercial and industrial animal production. It relies on private veterinarians, a variety of wholesalers and retailers (pharmacies, agricultural stores, etc.) including unprofessional ones, all tending to cluster in urban and peri-urban areas. 
515 Strategies have been implemented at the international level to improve drugs access in LMICs and the

516 efficiency of the drugs market chains. They provide "traditional" supports to the different functions of the national vet services. Significant effort has also been put into support of national legislations on veterinary drugs (in particular to include the issue of AMR), harmonization of the registration procedures of drugs in LMICs, and different arrangement to improve drugs availability (donation, vaccine banks) relying increasingly on Public/Private Partnerships and the involvement of pharmaceutical corporations in the drafting and implementation of public policies.

Several consequences can be drawn for AMR policies which intend to improve the whole animal farming market chain. First, analysis of antimicrobial use in animal farming should not rely primarily on farmer-veterinarian interactions and on cognitive or psychological factors that shape individual behaviors, because the use of drugs by farmers depends greatly on their accessibility. A policy targeting a decrease in antibiotic use where they are hardly available would be inefficient. This leads to identify the spots of low accessibility, which we can divide into is low availability (geographic accessibility, potential drugs deserts), quality (of drugs, advice, and medical equipment) and economic affordability. In particular, economic studies on affordability are much needed to understand the price formation process and how relative prices of drugs influence the decisions of the stakeholders of that chain. Second, the evolutions of setups of international policy for veterinary market chains shows that the commercial actors are playing a growing role in selecting the drugs that are made available and the conditions of their access. This has been made possible by the weak regulations of the market chains and the public veterinary services. Policies should carefully balance the interests of the various stakeholders, at the risk of reinforcing the selection of "interesting" diseases and the neglect of others that might be highly relevant for veterinary public health.

\section{Conflict of Interest}

538 The authors declare that the research was conducted in the absence of any commercial or financial 539 relationships that could be construed as a potential conflict of interest.

\section{Author Contributions}

\section{$541 \quad 7 \quad$ Funding}

542 This research has benefited from the funding of the French National Research Agency (ANR, to the project AMAGRI “Antimicrobiens en agriculture : acteurs, pratiques, conflits" (2019- 2020).

\section{Acknowledgments}

\section{References}

Abecassis, P., and N. Coutinet. 2019. Marché mondial du médicament : une forte dichotomie Nord/Sud. Diplomatie, Jan-Fev 201996.

African Union. 2018. The Chairperson of the African Union Commission inaugurates the Continental Veterinary Vaccine Bank. Communiqué, Jan. 31, 2018.

Akerlof, G. A. 1970. The Market for Lemons. Quality Uncertainty and the Market Mechanism. Quarterly Journal of Economics 84:488-500.

Alonso, C. A., M. Zarazaga, R. Ben Sallem, A. Jouini, K. Ben Slama, and C. Torres. 2017. Antibiotic resistance in Escherichia coli in husbandry animals: the African perspective. Letters in Applied Microbiology 64:318-334. 
Barry, M., B. Boidin, and S. Yaya. 2014. Les partenariats multipartites pour l'aide à la santé : fondements et ambiguïtés. Journal de gestion et d'économie médicales 32:308-326.

Baxerres, C. 2014. Du médicament informel au médicament libéralisé : une anthropologie du médicament pharmaceutique au Bénin. Archives Contemporaines, Paris.

Baxerres, C., M. Cassier, F. Chabrol, and C. Haxaire. 2017. Trente-cinq ans d'anthropologie du médicament en Afrique : retour sur l'étude des marchés informels, des hôpitaux et des usages pharmaceutiques. Anthropologie \& Santé 14.

Blancou, J., and M. Truszczynski. 1995. The role of international and regional organisations in the regulation of veterinary biologicals. Revue Scientifique Et Technique De L'Office International Des Épizooties 14:1193-1206.

Bonfiglioli, A. M. 1982. Ngaynaaaka : l'élevage selon les Wodaabe. USAID Niger.

Buse, K., and G. Walt. 2000. Global public-private partnerships- Part 1: a new development in health? Bulletin of the World Health Organization 78:549-561.

Catley, A., T. Leyland, J. C. Mariner, D. M. O. Akabwai, B. Admassu, W. Asfaw, G. Bekele, and H. S. Hassan. 2004. Para-veterinary professionals and the development of quality, self-sustaining community-based services. Revue Scientifique Et Technique De L'Office International Des Épizooties 23:225-252.

Cecchini, M., J. Langer, and L. Slawomirski. 2015. Antimicrobial resistance in G7countries and beyond: Economic Issues, Policies and Options for Action. OECD.

Chantziaras, I., F. Boyen, B. Callesn, and J. Dewulf. 2014. Correlation between veterinary antimicrobial use and antimicrobial resistance in food-producing animals: A report onseven countries. J Antimicrob Chemother 69::827-834.

Chauhan, A. S., M. S. George, P. Chatterjee, J. Lindahl, D. Grace, and M. Kakkar. 2018. The social biography of antibiotic use in smallholder dairy farms in India. Antimicrobial Resistance \& Infection Control 7:60.

CIRAD, and VSF. 2003. Document study on animal health auxiliaries. MAE, Agricultural Policies and Food Security Bureau, Paris.

Clark, M., and M. Embrey. 2012. Pharmaceutical donations.in M. S. F. Health, editor. MSD-3: Managing Access to Medicines and Health Technologies. Management Sciences for Health, Arlington.

Coutinet, N., and P. Abecassis. 2018. Les freins à la production locale et à l'accès aux traitements en Afrique. Pages 6-9 in Proparco, editor. Le médicament en Afrique : répondre aux enjeux d'accessibilité et de qualité. Secteur privé et développement, Paris.

Coyne, L. A., S. M. Latham, S. Dawson, I. J. Donald, R. B. Pearson, R. F. Smith, N. J. Williams, and G. L. Pinchbeck. 2018. Antimicrobial use practices, attitudes and responsibilities in UK farm animal veterinary surgeons. Preventive Veterinary Medicine 161:115-126.

Crosia, J. L. 2011. Worldwide market of veterinary drugs: Trends analysis for the last ten years and growth forecast. Bulletin De l'Académie Vétérinaire De France 164:21-25.

Dangy, L., and N. Fortané. 2016. Les frontières floues de l'expertise. Le cas de la normalisation du médicament vétérinaire Les Cahiers Droit, Sciences et Technologies 6:103-121.

Delgado, C., M. Rosegrant, H. Steinfeld, S. Ehui, and C. Courboi. 1999. Livestock to 2020 - The Next Food Revolution. Food. Agriculture and the Environment Discussion 28. 
597

598

599

600

601

602

603

604

605

606

607

608

609

610

611

612

613

614

615

616

617

618

619

620

621

622

623

624

625

626

627

628

629

630

631

632

633

634

635

636 637

Diop, B. A., and R. Bessin. 2004. Liens entre agents non professionnels et Services vétérinaires officiels en Afrique au Sud du Sahara. Rev. sci. tech. Off. int. Epiz. 23:147-156.

Dognon, S. R., N. Antoine-Moussiaux, C. Douny, P. Gustin, N. Moula, M. L. Scippo, and A. K. I. Youssao. 2018. The use of antibiotics in cattle in North-East Benin: pharmaceutical inventory and risk practices of cattle breeders. Tropical Animal Health and Production.

FAO. 2016. The FAO Action Plan on Antimicriobial Resistance 2016-2020. Supporting the food and agriculture sectors in implementing the Global Action Plan on Antimicrobial Resistance to minimize the impact of antimicrobial resistance. FAO, Rome.

FAO, and OMS. 2015. Commission du codex Alimentarius: Manuel de procédure 24 edition. FAO, Rome.

Fortané, N. 2020. Antimicrobial resistance: preventive approaches to the rescue? Professional expertise and business model of French "industrial" veterinarians. Review of Agricultural, Food and Environmental Studies.

Fortané, N. 2016. The Public Problem of Antimicrobial Resistance in Livestock: Genealogy and Characterisation. Questions de communication.

Fortané, N., F. Bonnet-Beaugrand, A. Hémonic, C. Samedi, A. Savy, and C. Belloc. 2015. Learning Processes and Trajectories for the Reduction of Antibiotic Use in Pig Farming: A Qualitative Approach. Antibiotics 4:435-454.

Galière, M., M. Peyre, F. Muñoz, M. Poupaud, A. Dehove, F. Roger, and I. Dieuzy-Labaye. 2019. Typological analysis of public-private partnerships in the veterinary domain. PLOS One 14:e0224079.

GALVMed. 2016. Regulatory harmonisation: Improving access to safe, effective and quality veterinary medicines across East Africa.

GALVMed. 2015. Review of requirements and processes for registration of veterinary products in selected African and Asian countries.

Gateaux, V., and H. Jean-Michel. 2008. L'accès aux médicaments: un défi pour l'industrie pharmaceutique. Humanisme et Entreprise 28:13-28.

Goutard, F., M. Bordier Bouchot, C. Calba, E. Erlacher-Vindel, D. Góchez, K. de Balogh, C. Benigno, W. Kalpravidh, F. Roger, and S. Vong. 2017. Antimicrobial policy interventions in food animal production in South East Asia BMJ. British Medical Journal 358:36-41.

Grasswitz, T. R., T. J. Leyland, J. T. Musiime, O. S.J., and K. R. Sones, editors. 2004. The veterinary pharmaceutical industry in Africa: a study of Kenya, Uganda and South Africa. African Union. Interafrican Bureau for Animal Resources (AU/IBAR), Nairobi, Kenya.

Guilbaud, A. 2015a. Business partners: firmes privées et gouvernance mondiale de la santé. Presses de Sciences Po, Paris.

Guilbaud, A. 2015b. Les partenariats public-privé sanitaires internationaux : diffusion et incarnation d'une norme de coopération. Mondes en développement, 2:91-104.

Guilloux, A., and S. Moon 2001. Hidden Price Tags: Disease-Specific Drug Donations: Costs and Alternatives. MSF/DND Working Group:189-2010.

Gustafson, R. H., and R. E. Bowen. 1997. Antibiotic use in animal agriculture. Journal of Applied Microbiology 83:531-541. 
638

639

640

641

642

643

644

645

646

647

648

649

650

651

652

653

654

655

656

657

658

659

660

661

662

663

664

665

666

667

668

669

670

671

672

673

674

675

676

677

678

679

HealthforAnimals. 2017. Illegal Veterinary Medecines. Impact on effective control. HealthforAnimals, Bruxelles.

Hockenhull, J., A. E. Turner, K. K. Reyher, D. C. Barrett, L. Jones, S. Hinchliffe, and H. J. Buller. 2017. Antimicrobial use in food-producing animals: a rapid evidence assessment of stakeholder practices and beliefs. Vet Rec.

Hogerzeil, H. V. 1997. Guidelines for drug donations. BMJ. British medical journal (Clinical research ed.) 314:737.

Holmes, M., and R. E. Hill. 2007. International harmonisation of regulatory requirements. Revue Scientifique Et Technique-Office International Des Epizooties 26:415-420.

ILRI. 2012. Mapping of Poverty and Likely Zoonoses Hotspots. ILRI, Report to Department for International Development (DFID), UK.

Ilukor, J. 2017. Improving the delivery of veterinary services in Africa: insights from the empirical application of transaction costs theory in Uganda and Kenya. Rev. sci. tech. Off. int. Epiz. 36:279-289.

Khan, M. S., A. Durrance-Bagale, H. Legido-Quigley, A. Mateus, R. Hasan, J. Spencer, and J. Hanefeld. 2019. 'LMICs as reservoirs of AMR': a comparative analysis of policy discourse on antimicrobial resistance with reference to Pakistan. Health Policy and Planning.

Kingsley, P. 2012. Fake animal drugs threaten African livestock and livelihoods. The Conversation.

L'Économiste. 2008. Médicaments vétérinaires. Les oubliés de la réforme. L'Économiste, Maroc.

Landais, E. 1990. Sur les doctrines des vétérinaires français coloniaux en Afrique noire. Cahier des Sciences Humaines 26:33-71.

Le Minor, O. 2011. L'Asie du Sud-Est, un foyer pandémique ? Le médicament vétérinaire en question. IRASEC, Bangkok.

Lhermie G., R. D., Krebs S., Dupraz P. 2015. Facteurs déterminants et leviers de réduction de l'usage des antibiotiques en productions animales. Économie Rurale 348:3-22.

Lombard, M., and A. E. Füssel. 2007. Antigen and vaccine banks: technical requirements and the role of the european antigen bank in emergency foot and mouth disease vaccination. Rev Sci Tech 26:117-134.

Luseba, D., and P. Rwambo. 2015. Review of the policy, regulatory and administrative framework for delivery of livestock health products and services in Eastern and Southern Africa. prepard for GALVMed. GALVMed, UK.

Magnani, S., B. Bonnet, R. Lancelot, and R. Metras. 2018. Amélioration de la santé animale en zone sahélienne. Fonctionnement et structure des services vétérinaires Gestion des maladies transfrontalières. Note de cadrage. . 3è édition des Entretiens techniques du PRAPS (ETP3). Projet Régional d'Appui au Pastoralisme au Sahel, Ouagadougou, Burkina Faso.

Marion, H. 2012. Antimicrobial resistance and the guidelines of the International Cooperation on Harmonisation of Technical Requirements for Registration of Veterinary Medicinal Products (VICH) Rev. sci. tech. Off. int. Epiz. 1(31): 299-306.

Masud, A. A., E. K. Rousham, M. A. Islam, M.-U. Alam, M. Rahman, A. A. Mamun, S. Sarker, M. Asaduzzaman, and L. Unicomb. 2020. Drivers of Antibiotic Use in Poultry Production in Bangladesh: Dependencies and Dynamics of a Patron-Client Relationship. Frontiers in Veterinary Science 7. 
680

681

682

683

684

685

686

687

688

689

690

691

692

693

694

695

696

697

698

699

700

701

702

703

704

705

706

707

708

709

710

711

712

713

714

715

716

717

718

McCorkle, C. M. 1995. Back to the future: lessons from ethnoveterinary RD\&E for studying and applying local knowledge. Agriculture and Human Values 12:52-80.

Mendelson, M., J. Rottingen, U. Gopinathan, and e. al. 2016. Maximising access to achieve appropriate human antimicrobial use in low-income and middle-income countries. Lancet 387:188-198.

Merrett, G. L. B., G. Bloom, A. Wilkinson, and H. MacGregor. 2016. Towards the just and sustainable use of antibiotics. Journal of Pharmaceutical Policy and Practice 9.

Mwale, M., and P. J. Masika. 2009. Ethno-veterinary control of parasites, management and role of village chickens in rural households of Centane district in the Eastern Cape, South Africa. Tropical Animal Health and Production 41:1685-1693.

Ndour, M. 2006. Partenariats public-privé mondiaux pour la santé : l'émergence d'une gouvernance transnationale des problèmes de santé des pays en développement ? Iddri.

Niang, A. B. 2004. Successful privatisation of para-professional services in traditional livestock farming systems: the case of Senegal. Revue Scientifique Et Technique De L'Office International Des Épizooties 23:341-349.

OECD. 2016. Antimicrobial resistance. Policy insights.

OIE. 1992. Manual of standards for diagnostic tests and vaccines. Paris.

OIE. 2018a. OIE Policy Paper on Vaccine Banks. OIE, Paris.

OIE. 2018b. Pastoralism and Sanitary Challenges. OIE, Paris.

OIE. 2018c. Vaccine banks.

OIE. 2019. The OIE PPP Handbook: Guidelines for Public-Private Partnerships in the veterinary domain. OIE, Paris.

Orand, J.-P. 2012. Normes de l'Organisation mondiale de la santé animale et besoins futurs. Revue Scientifique et Technique de l'Office International des Épizooties 31:325-334.

Peeling, D., and S. Holden. 2004. The effectiveness of community-based animal health workers, for the poor, for communities for public safety. Revue Scientifique Et Technique De L'Office International Des Épizooties 23:253-276.

Peterson, K. 2014. Speculative markets. Drugs circuits and derivative life in Nigeria. Duke University Press, Durham and London.

Porphyre, V., M. Rakotoharinome, T. Randriamparany, D. Pognon, S. Prévost, and B. Le Bizec. 2013. Residues of medroxyprogesterone acetate detected in sows at a slaughterhouse, Madagascar. Food Additives \& Contaminants: Part A 30:2108-2113.

Quet, M. 2018. Impostures pharmaceutiques. Médicaments illicites et luttes pour l'accès à la santé. La Découverte, Paris.

Reynolds Whyte, S., S. van der Geest, and A. Hardon. 2002. Social lives of medicines. Cambridge University Press, Cambridge.

Roger, F., and P. Bonnet. 2015. Control of endemic tropical diseases Identifying certain animal diseases as "neglected". Perspective, Policy Brief 15.

Roulette, C. J., M. A. Caudell, J. W. Roulette, R. J. Quinlan, M. B. Quinlan, M. Subbiah, and D. R. Call. 2017. A two-month follow-up evaluation testing interventions to limit the emergence and 
spread of antimicrobial resistant bacteria among Maasai of northern Tanzania. Bmc Infectious Diseases 17:10.

Rubyogo, J. C., P. M. Murithii, G. J. O. Agumbah, and G. Obhai. 2005. Sustainability of a privatized Community-based Animal Health Worker system in Mwingi District, Kenya. Tropical Animal Health and Production 37:253-266.

Schouten, E. 1995. Drug donations must be strictly regulated. BMJ:311-684.

Smith, M. V. 2013. The role of veterinary medicine regulatory agencies. Revue scientifique et tecnique - Office International epizooties 32:393-408.

Sunderji, N. 2017. L'indispensable transformation des chaînes d'approvisionnement dans le secteur pharmaceutique subsaharien in Proparco, editor. Le médicament en Afrique : répondre aux enjeux d'accessibilité et de qualité. Secteur privé et développement, Paris.

Tagliaro, A. 2016. Banques de vaccins régionales de l'OIE. 12ème Réunion du CPC du REMESA OIE, Espagne.

Thevasagayamn, S. J., I. Dieuzy-Labaye, and E. Tagliaro. 2017. Partenariats public-privé : attentes des partenaires privés concernant la santé animale au niveau international et les programmes de développement de l'élevage. OIE, Paris.

Thompson, S. 1999. International Harmonization Issues. Veterinary clinics of north America: Food animal practice 15:181-195.

Van Boeckel, T. P., C. Brower, M. Gilbert, B. T. Grenfell, S. A. Levin, T. P. Robinson, A. Teillant, and R. Laxminarayan. 2015. Global trends in antimicrobial use in food animals. Proceedings of the National Academy of Sciences 112:5649-5654.

Van Boeckel, T. P., J. Pires, R. Silvester, C. Zhao, J. Song, N. G. Criscuolo, M. Gilbert, S. Bonhoeffer, and R. Laxminarayan. 2019. Global trends in antimicrobial resistance in animals in low- and middle-income countries. Science 365: eaaw1944.

Vougat Ngom, R. R. B., T. Tomdieu, R. Ziébé, H. S. Foyet, M. Moritz, L. Vondou, D. E. Schrunk, P. M. Imerman, W. K. Rumbeiha, and R. B. Garabed. 2017. Quality of veterinary pharmaceuticals and their use by pastoralists in the Far North Region of Cameroon. Pastoralism-Research Policy and Practice 7:6.

WHO. 1999. Interagency Guidelines: Guidelines for drug donations. WHO, Geneva.

WHO. 2003. Joint FAO/OIE/WHO Expert Workshop on Non-Human Antimicrobial Usage and Antimicrobial Resistance: Scientific Assessment. December 1-5, 2003. Expert Workshop on Non-Human Antimicrobial Usage and Antimicrobial Resistance, Geneva.

WHO, FAO, and OIE. 2017. WHO, FAO, and OIE unite in Antimicrobial Resistance the fight against Antimicrobial Resistance. Political Declaration of the High -level Meeting of the General Assembly on Antimicrobial Resistance.

Zoetis. 2019. African Livestock Productivity and Health Advancement. Zoetis. 